\title{
In Vitro Biocompatibility of Electrospun Poly( $\varepsilon$-Caprolactone)/Cellulose Nanocrystals-Nanofibers for Tissue Engineering
}

\author{
Sayan Deb Dutta, ${ }^{1}$ Dinesh K. Patel, ${ }^{2}$ Yu-Ri Seo, ${ }^{1}$ Chan-Woo Park, ${ }^{3}$ Seung-Hwan Lee, ${ }^{3}$ \\ Jin-Woo Kim $(1),{ }^{4}$ Jangho Kim, ${ }^{5}$ Hoon Seonwoo ${ }^{10},{ }^{6}$ and Ki-Taek Lim ${ }^{1}{ }^{1}$ \\ ${ }^{1}$ Department of Biosystems Engineering, College of Agriculture and Life Sciences, Kangwon National University, \\ Chuncheon 24341, Republic of Korea \\ ${ }^{2}$ The Institute of Forest Science, Kangwon National University, Chuncheon 24341, Republic of Korea \\ ${ }^{3}$ Department of Forest Biomaterials and Engineering, Kangwon National University, Chuncheon 24341, Republic of Korea \\ ${ }^{4}$ Department of Biological and Agricultural Engineering, Institute of Nanoscience and Engineering, University of Arkansas, \\ Fayetteville AR-72701, USA \\ ${ }^{5}$ Department of Rural and Biosystems Engineering, Chonnam National University, Gwangju 61186, Republic of Korea \\ ${ }^{6}$ Department of Industrial Machinery Engineering, Sunchon National University, Suncheon 57922, Republic of Korea \\ Correspondence should be addressed to Ki-Taek Lim; ktlim@kangwon.ac.kr
}

Received 27 February 2019; Revised 6 July 2019; Accepted 3 September 2019; Published 15 October 2019

Academic Editor: David Cornu

Copyright ( 2019 Sayan Deb Dutta et al. This is an open access article distributed under the Creative Commons Attribution License, which permits unrestricted use, distribution, and reproduction in any medium, provided the original work is properly cited.

\begin{abstract}
Cellulose nanocrystals (CNCs) have emerged as promising materials for the fabrication of micro/nanoplatforms that can replace tissues more effectively. CNCs offer interesting properties that facilitate the enhancement of polymer properties. Cytotoxicity of rice husk-derived CNCs was evaluated through WST-1 assay in the presence of human mesenchymal stem cells. Electrospinning

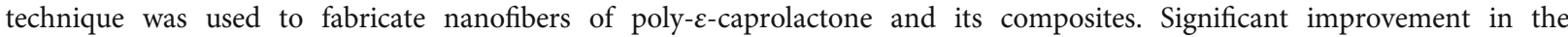
mechanical property was observed in the composites relative to the pure polymer. This improvement was attributed to the better interfacial interactions between the polymer matrix and CNCs. Notably, better cell viability and differentiation were observed with the composite nanofibers than with the pure polymers. The osteogenic potential of the fabricated nanofibers was assessed by alizarin red S staining and real-time PCR. Enhanced mineralization occurred in the presence of the composite rather than pure polymer nanofibers. Furthermore, the higher levels of osteogenic markers observed with the media containing the composites clearly indicated their osteogenic potential. These results suggested that fabricated composites have the potential to be used as a biomaterial for tissue engineering applications.
\end{abstract}

\section{Introduction}

Various materials have been utilized to fabricate scaffolds as an extracellular matrix (ECM) for tissue engineering [1]. Scaffold architecture and fabrication are essential for tissue engineering and regenerative medicine. For the ECM application, materials should have a porous structure with adequate mechanical strength. Besides, biocompatibility and degradation potentials are critical parameters for the ECM [2-4]. Several techniques are used for the fabrication of scaffolds for tissue engineering applications. Among them, the electrospinning technique has drawn considerable attention for high-quality scaffold fabrication [3]. This technique allows for the production of polymer fibers with diameters in the order of a few nanometers to $>1 \mu \mathrm{m}$ [5]. The electrospinning fibers are prepared by mixing the filler solution in the polymer matrices to improve the fundamental properties of the polymers [6, 7]. Poly- $\varepsilon$-caprolactone (PCL), a biodegradable polymer, has been extensively used for scaffold fabrication due to its superior physiochemical 


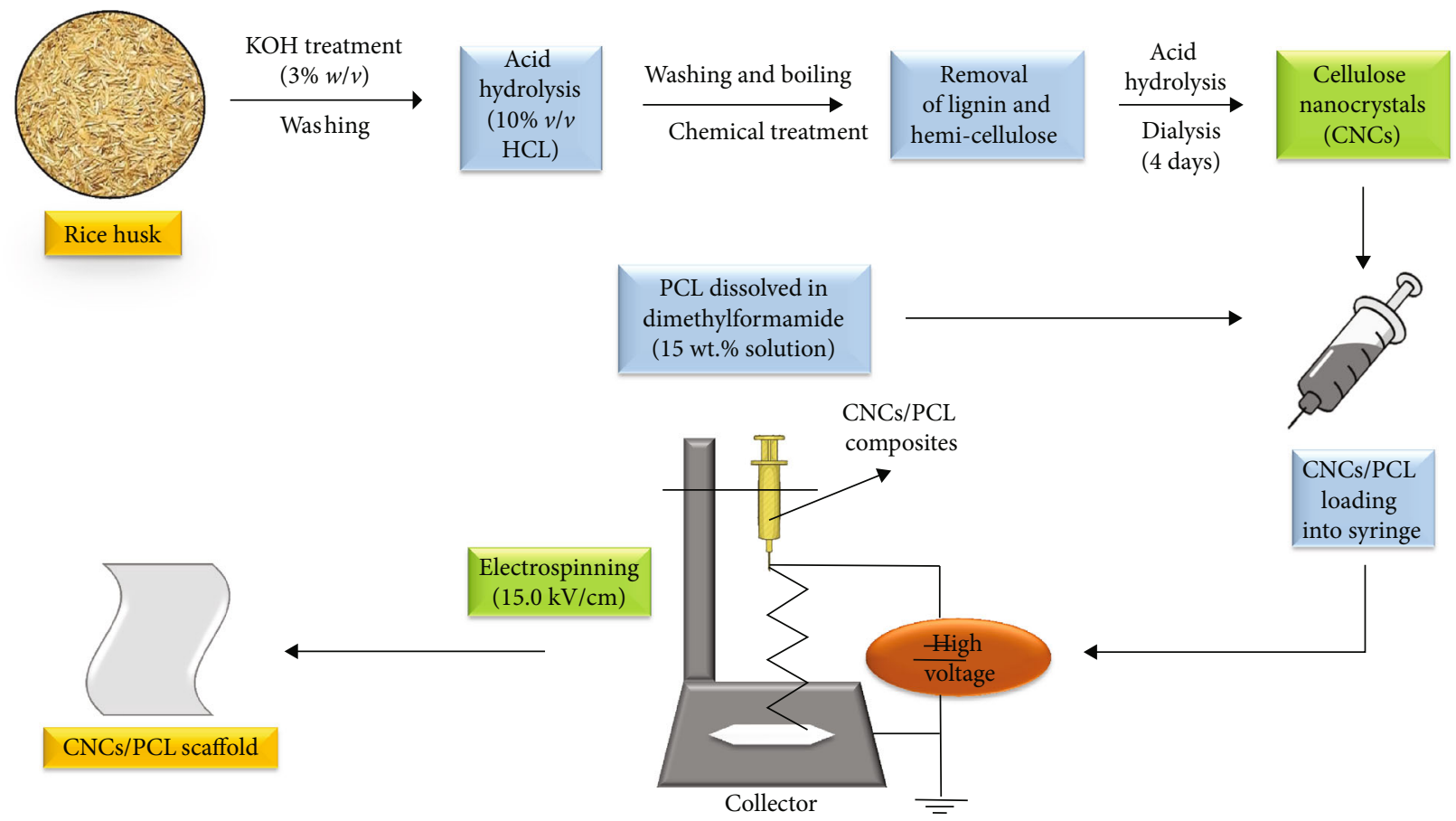

FIGURE 1: Schematic representation of fabrication of PCL/CNC composite fiber through the electrospinning process.

properties [8]. However, the hydrophobic nature of PCL restricts its broad-spectrum use for scaffold fabrication in tissue engineering [9]. This drawback can be overcome by using the appropriate filler material in the polymer matrices. Several materials, such as nanocellulose, clay, and layered double hydroxide (LDH), have been extensively used for altering the properties of a native polymer [10]. Of these, nanocellulose has received considerable attention for scaffold fabrication owing to its excellent physiochemical properties [11]. Using the advantages of cellulose nanocrystals (CNCs), it is possible to fabricate a high-performance biomaterial with PCL for tissue engineering [12]. An enhancement in the mechanical properties has been reported for CNC-based polymer composites compared with those of the pure polymer [13]. CNC-based polymer composites have shown enormous potential, and they can be utilized in various fields [14]. Rice husk CNCs have been noted to have higher reinforcing efficiency in plasticized starch biocomposites than other fillers [15]. Polymer/CNC composites have been extensively investigated over the recent decades for their use in tissue engineering [16]. It has been noted that electrical stimulus induces cell differentiation in the presence of CNC moieties [17]. Herein, we have extracted CNCs from rice husk, and nanofibers made of $\mathrm{PCL} / \mathrm{CNC}$ composites were prepared by the electrospinning technique. Enhancement in cellular response occurred in the presence of the composite fiber rather than the pure polymer. Figure 1 shows the schematic diagram for isolation as well as fabrication of the PCL/CNC composite fiber.

\section{Materials and Methods}

2.1. Extraction of CNCs from Rice Husk. Rice husk powder was prepared by the mill (A10, IKA, Germany). To remove the silica content, the rice husk powder $(10 \mathrm{~g})$ was stirred with $3 \%(w / v)$ potassium hydroxide $(\mathrm{KOH} ; \geq 85 \%$, Sigma-Aldrich, USA; CAS: 1310-58-3) at a weight ratio of $1: 12$ and boiled for $30 \mathrm{~min}$ [18, 19]. Afterward, the potassium hydroxide-treated rice husk was washed with distilled water followed by neutralization with the $10 \%(v / v)$ hydrochloric acid solution ( $\mathrm{HCl}$; Fujifilm Wako Pure Chemical Co., Japan; CAS: 7647-01-0). Finally, the obtained material was washed with distilled water and dried for further analyses. Next, the obtained material $(6.24 \mathrm{~g}$ dry powder) was treated with distilled water $(1: 60 \mathrm{~g}$ solid $/ \mathrm{ml}$ liquor) and boiled at $80^{\circ} \mathrm{C}$ for $30 \mathrm{~min}$. To remove the lignin byproduct, the suspension was treated with sodium chloride (>73\%, Daejung, Republic of Korea; CAS: 7758-19-2) and acetic acid in a ratio of $1.2 \mathrm{~g}$ to $240 \mu \mathrm{l} / \mathrm{g}$ of the solid material present in the suspension, respectively, and continuously stirred for $1 \mathrm{~h}$ [20]. This process was repeated 6 times. The residue material was washed with distilled water followed by freeze-drying for 24h (Freeze Dryer, EYELA ${ }^{\circledR}$ Freeze Drying Unit 2200, Tokyo Rikakikai Co., Japan). The hemicellulose content was removed by treating the obtained residue material (4.42 g) with $17.5 \%$ $(w / v)$ sodium hydroxide $(\mathrm{NaOH} ; \geq 89 \%$, Sigma-Aldrich, USA; CAS: 1310-73-2) solution for $50 \mathrm{~min}$ followed by the addition of $10 \%(v / v)$ acetic acid solution for neutralization. Afterward, the residue material was washed with distilled water as above ( $2.9 \mathrm{~g}$ solid material). Cellulose hydrolysis was performed using the $64 \%(w / w)$ sulfuric acid $\left(\mathrm{H}_{2} \mathrm{SO}_{4}\right.$; Daejung, Republic of Korea; CAS: 7664-93-9) at $45^{\circ} \mathrm{C}$ for $60 \mathrm{~min}$. The obtained material was dialyzed with a cellulose tube for 4 days. The photographs of the pure rice husk and the chemically treated samples are shown in Supplementary Figure 1.

2.2. Spectroscopic, Thermal, and Size Characterization of CNCs. Fourier-transform infrared (FTIR; Frontier, Perkin 


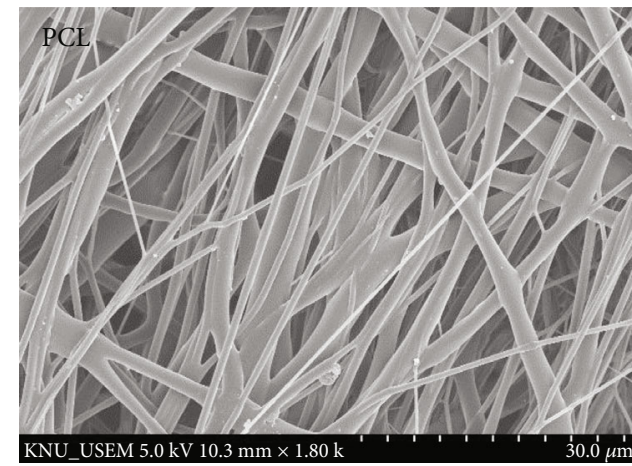

(a)

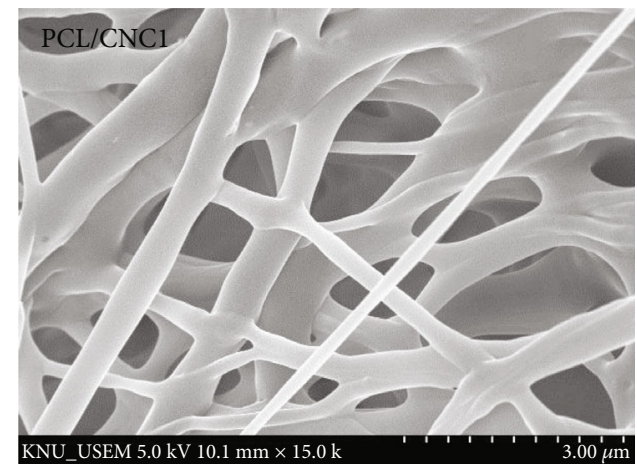

(b)

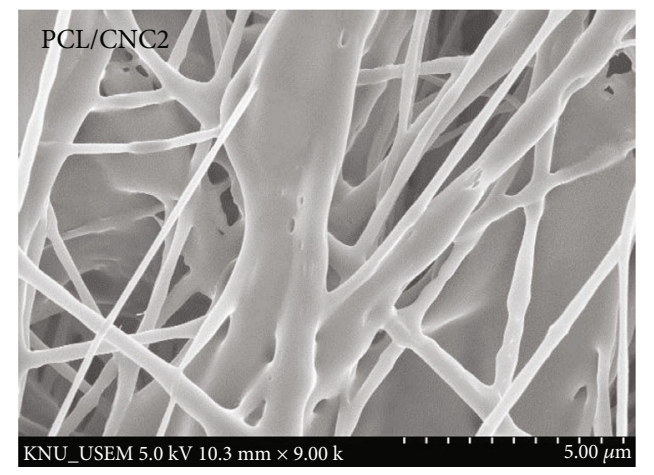

(c)

FIGURE 2: FE-SEM morphologies of the fabricated nanofibers of PCL and indicated composites.

Elmer, UK) spectra of the chemically treated and untreated rice husk were obtained in transmission mode with 16 scans. FTIR measurements were taken in the wavenumber range of $500-4000 \mathrm{~cm}^{-1}$ at a resolution of $4 \mathrm{~cm}^{-1}$. The thermal stability of the extracted CNCs was evaluated by using thermogravimetric analyzer (TGA) in the range of $40-500^{\circ} \mathrm{C}$ with a heating rate of $10^{\circ} \mathrm{C} / \mathrm{min}$ (SDT Q600, TA Instruments, USA). The dimensions (including its shape and size distribution) of the CNCs were measured by transmission electron microscopy (TEM; JEM 2100F, Jeol, Japan). For this, the CNCs were dispersed in deionized water by sonication. A drop of diluted CNC aqueous suspension was deposited on a microgrid and air-dried for $30 \mathrm{~min}$. The grid was negatively stained with uranyl acetate and air-dried. The dimensions of the CNCs were measured by ImageJ (Version 1.8.0., NIH Portal, Maryland, USA).

2.3. Preparation of the PCL/CNC Composite. Polycaprolactone (PCL; $\geq 95 \%$, Sigma-Aldrich, USA; CAS: 24980-41-4) with an average molecular weight of $80,000 \mathrm{~g} / \mathrm{mole}$ was used for preparing the PCL/CNC composites. PCL was dissolved in dimethylformamide (DMF; Daejung, Republic of Korea; CAS: 68-12-2) to obtain a 15 wt.\% solution. Different amounts of CNCs (e.g., $0.5 \%, 1 \%$, and $2 \%$ ) were blended with PCL. For electrospinning, PCL/CNC solution was loaded into a $10 \mathrm{~cm}^{3}$ plastic syringe. The solution was delivered at a constant flow rate to a high voltage power supply to make the PCL/CNC nanofibers. When a high voltage $(18.0 \mathrm{kV} / \mathrm{cm})$ was applied, a Taylor cone jet with a flow rate of $2 \mathrm{ml} / \mathrm{h}$ was ejected from the tip of the syringe.
2.4. Morphology of the Fabricated Nanofibers. Scanning electron microscopy (SEM) was used to evaluate the 2D morphology of the electrospun nanocomposites. For SEM observation, all the materials (PCL, PCL/CNC0.5, PCL/CNC1, and PCL/CNC2) were sputter-coated with platinum and observed by field emission-SEM (FE-SEM; Hitachi S-4800, California, USA) with an acceleration voltage of $5.0 \mathrm{kV} / \mathrm{cm}$. The morphology of the electrospun nanocomposites is given in Figure 2.

2.5. Mechanical Properties of the PCL/CNC Scaffolds. The mechanical properties of the fabricated scaffolds were evaluated through a tensile test. The tensile testing was carried out in a universal testing machine (UTM; MCT-1150, AND Inc., Japan). The test was performed using a constant speed of $10 \mathrm{~mm} / \mathrm{min}$. All the samples were prepared in triplicate.

\subsection{In Vitro Studies}

2.6.1. Cell Culture. The human bone marrow-derived mesenchymal stem cells (hMSCs) were obtained from the Korean Cell Line Bank (KCLB, Seoul, Republic of Korea). Cell culture was carried out using Dulbecco's modified Eagle's medium (DMEM; WELGENE, Republic of Korea; CAS: LM-001-05) with $10 \%$ fetal bovine serum (FBS; WELGENE, Republic of Korea; CAS: S-101-101) and the antibiotic-antimycotic mixture (Anti-Anti; 100X, Gibco, USA; CAS: 15-240-062) containing penicillin $(10,000$ units/ml), streptomycin $(10,000 \mu \mathrm{g} / \mathrm{ml})$, and amphotericin B $(25 \mu \mathrm{g} / \mathrm{ml})$. The hMSCs were incubated at $37^{\circ} \mathrm{C}$ in a humidified atmosphere of $5 \% \mathrm{CO}_{2}$ (Steri-Cycle 
TABLE 1: Specified primer sequences used for quantitative real-time PCR (qRT-PCR).

\begin{tabular}{lc}
\hline Gene & Sequences $\left(5^{\prime}\right.$ to $\left.3^{\prime}\right)$ \\
\hline HPRT & GGCTATAAGTTCTTTGCTGACCTG \\
& CCACAGGGACTAGAACACCTGCTA \\
RUNX2 & CGCATTCCTCATCCCAGTAT \\
& GACTGGCGGGGTGTAAGTAA \\
OSX & TGCTTGAGGAGGAAGTTCAC \\
& AGGTCACTGCCCACAGAGTA \\
COL1 & CTGACCTTCCTGCGCCTGATGTCC \\
& GCN
\end{tabular}

HPRT: hypoxanthine-guanine phosphoribosyl transferase; RUNX2: Runtrelated transcription factor 2; OSX: Osterix; COL1: collagen type 1; OCN: osteocalcin.

370 Incubator; Thermo Fisher Scientific, USA). Culture medium was replaced with fresh medium every three days during the experiment. After confluence, hMSCs were detached, they were rinsed with Dulbecco's phosphate-buffered saline (DPBS; WELGENE, Republic of Korea; CAS: LB-001-04), and then $1 \mathrm{ml}$ of $0.25 \%$ of trypsin-ethylenediaminetetraacetic acid (EDTA; Gibco, USA; CAS: 25200056) solution was added. Cells were used when they were between passages 3 and 5. For osteogenic induction, cells were cultured in the control medium containing $50 \mu \mathrm{g} / \mathrm{ml}$ L-ascorbic acid (Sigma-Aldrich, USA; CAS: 50-81-7), $10 \mathrm{mM} \beta$-glycerophosphate (Sigma-Aldrich, USA; CAS: 154804-51-0), and $100 \mathrm{nM}$ dexamethasone (Sigma-Aldrich, USA; CAS: 50-02-2).

2.6.2. Cell Viability and Proliferation Assay. The fabricated PCL/CNC composites at different CNC concentrations (e.g., $0 \% \mathrm{CNC}, 0.5 \% \mathrm{CNC}, 1 \% \mathrm{CNC}$, and $2 \% \mathrm{CNC}$ ) were added into wells of a 24 -well plate and incubated at $37^{\circ} \mathrm{C}$ with $5 \% \mathrm{CO}_{2}$ (Steri-Cycle 370 Incubator; Thermo Fisher Scientific, USA). The hMSCs $\left(4 \times 10^{6}\right.$ cells/well $)$ without the scaffolds were used as a control. The cell viability on the scaffolds was analyzed using the WST-1 assay following incubation up to 14 days. The metabolically active hMSCs react with the WST1 reagent to produce a formazan dye that can be quantitated by measuring the absorbance at $450 \mathrm{~nm}$ using a spectrophotometer (Infinite ${ }^{\circledR}$ M Nano 200 Pro; TECAN, Switzerland). After cell culture, the hMSCs were washed twice in DPBS. Then, $100 \mu \mathrm{l}$ of the WST-1 reagent (EZ-Cytox Cell Viability Assay $\mathrm{Kit}^{\circledR}$; DoGenBio Co., Ltd., Republic of Korea) was added into each well and the samples were incubated for an additional $3 \mathrm{~h}$. Next, $100 \mu \mathrm{l}$ of each of these samples was transferred onto a well of a 96-well plate (Eppendorf Ltd., Germany), and the absorbance was measured at $450 \mathrm{~nm}(625 \mathrm{~nm}$ as a reference value). All the samples were prepared in triplicate, and data are presented as mean ODs \pm standard deviations.

2.6.3. Assessment of Cell-Matrix Adhesion. To study the cellmatrix interaction of hMSCs with fabricated scaffolds, scanning electron microscopy (SEM) was performed. Samples were prepared by a modified protocol described by Lee and Chow [21]. Briefly, the cells were seeded in a $35 \times 10 \mathrm{~mm}$ cul- ture dish with PCL/CNC composites and incubated with 5\% $\mathrm{CO}_{2}$ at $37^{\circ} \mathrm{C}$. After 5 days, cells were washed with $1 \times$ Dulbecco's phosphate-buffered saline (DPBS; WELGENE, Republic of Korea; CAS: LB 001-04) two times and fixed with $2 \%$ paraformaldehyde (PFA; Reagent grade; Sigma-Aldrich, USA; CAS: $30525-89-4)$ and 2\% glutaraldehyde (EM grade; Sigma-Aldrich, USA; CAS: $111-30-8)$ for $1 \mathrm{~h}$ at $4^{\circ} \mathrm{C}$. The fixed cells were washed two times with $1 \times$ DPBS and dehydrated with sequential washes of ethanol (Molecular Grade; Sigma-Aldrich, USA; CAS: 64-17-5) at the following percentages: $30 \%(5 \mathrm{~min}), 50 \%$ ( $5 \mathrm{~min}$ ), $70 \%$ ( $5 \mathrm{~min}$ ), $80 \%$ ( $3 \mathrm{~min}$ ), $90 \%$ ( $3 \mathrm{~min}$ ), and $100 \%$ (30 s). After dehydration, the samples were subjected to freeze-drying (Freeze Dryer, EYELA ${ }^{\circledR}$ Freeze Drying Unit 2200, Tokyo Rikakikai Co., Japan) prior to SEM analysis. For SEM, samples were sputter-coated with platinum and images were visualized by a field emission scanning electron microscope (FE-SEM; Hitachi S4800, California, USA).

2.6.4. Alizarin Red S (ARS) Staining. Enhanced osteogenic activity of fabricated PCL/CNC composites in the presence of hMSCs was measured by ARS staining (Sigma-Aldrich, USA; CAS: 130-22-3) after 7 and 14 days of incubation. The media were replaced every 3 days. Passage 4 cells were used for cell seeding. After cell culture, the hMSCs were fixed in $4 \%$ formalin for $15 \mathrm{~min}$, rinsed with distilled water, and stained with $40 \mathrm{mM}$ alizarin red S ( $\mathrm{pH} 4.2$ ) stain. The mineralization was documented using an optical microscope (Zeiss, USA). Excess dye was removed by washing the plates with deionized water four times. The remaining dye was dissolved in $500 \mu \mathrm{l}$ of destaining solution (10\% cetylpyridinium chloride and $10 \mathrm{mM}$ sodium phosphate). The absorbance of the solution was analyzed at $562 \mathrm{~nm}$ using a spectrophotometer (Infinite ${ }^{\circledR}$ M Nano 200 Pro; TECAN, Switzerland). All the samples were prepared in triplicate, and data are presented as mean ODs \pm standard deviations.

2.6.5. RNA Isolation and Quantitative Real-Time PCR ( $q R T-P C R)$ Analysis. To study the gene expression in both PCL/CNC composites and control samples, cells were seeded in a $60 \times 15 \mathrm{~mm}$ culture dish and cultured under the osteogenic induction medium with $5 \% \mathrm{CO}_{2}$ at $37^{\circ} \mathrm{C}$. Total RNA was extracted by TRIzol ${ }^{\circledR}$ reagent (Thermo Fisher Scientific, USA; CAS: 15596026) according to the manufacturer's instructions. RNA sample purity and concentration were determined by a spectrophotometer (Infinite ${ }^{\circledR}$ M Nano 200 Pro; TECAN, Switzerland). Then, $2 \mu \mathrm{g}$ of total RNA was used to synthesize cDNA using reverse transcriptase (Superscript II RTase; Invitrogen, Gaithersburg, MD; CAS: 18064014) and SYBR Green Master Mix (Bio-Rad, USA; CAS: 10000076382). cDNA synthesis was carried out using a fast heating-cooling system (Dry-Bath Heating System, Daihan Scientific Co., Korea). The mRNA expression was quantified with qRT-PCR using a Bio-Rad Real-Time PCR $\left(\right.$ CFX96 $^{\mathrm{TM}}$ Maestro Real-Time System, Bio-Rad, USA). The reaction conditions included 43 cycles of denaturation for $15 \mathrm{~s}$ at $95^{\circ} \mathrm{C}$ and $1 \mathrm{~min}$ amplification at $60^{\circ} \mathrm{C}$. All the reactions were performed in triplicate and normalized to the housekeeping gene hypoxanthine-guanine phosphoribosyltransferase 


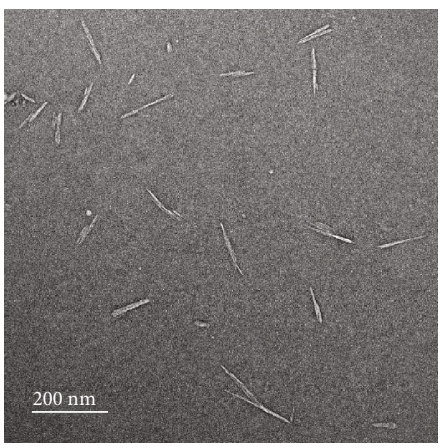

(a)
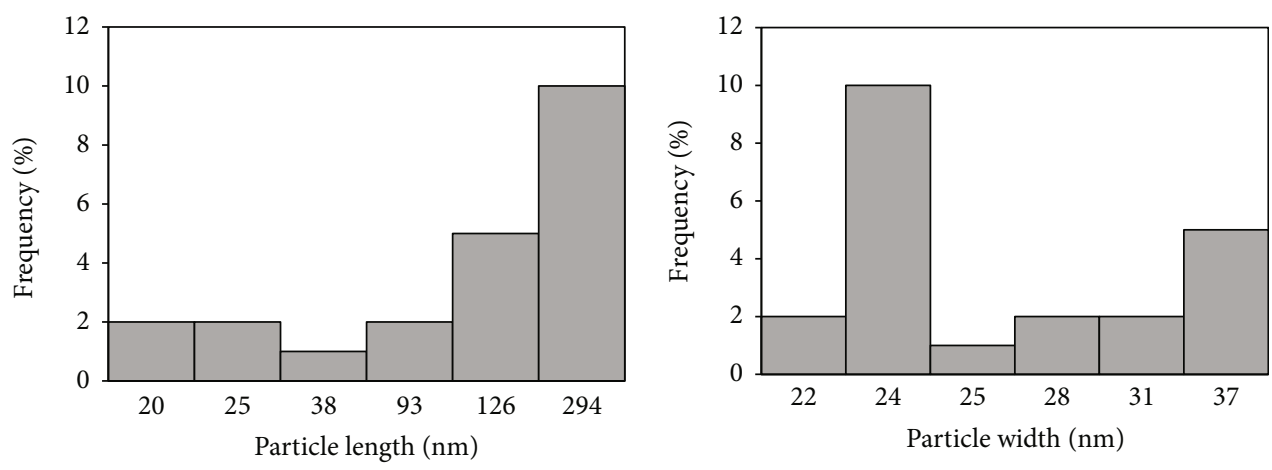

(b)

Figure 3: (a) TEM images of rice husk-derived CNCs and (b) length and width distribution histogram of sulfuric acid hydrolyzed CNCs.

(HPRT). To study the gene expression levels of the control and PCL/CNC-treated groups, the cycle threshold values were calculated and compared. The relative mRNA expression in the control hBM-MSCs and PCL/CNC-treated cells was compared in a histogram. All the samples were prepared in triplicate during the experiments. The specific primer sets (e.g., RUNX2, OSX, OCN, and COL1) are listed in Table 1. All the primers were synthesized by BIONEER ${ }^{\circledR}$ Inc. (Daejeon, Republic of Korea).

2.6.6. Statistical Analysis. Statistical analysis was performed using SAS for Windows v8.2 (SAS Institute., Cary, NC, USA). Statistical significance between the control and treatment groups was determined using ANOVA, Duncan's multiple range test, and Mann-Whitney rank sum tests. All the data are presented as mean \pm SDs. Differences were considered significant at $P<0.05$.

\section{Results and Discussion}

3.1. Spectroscopic Characteristic and Thermal Behavior of Treated Rice Husk. The FTIR spectra of rice husk before and after purification are given in Supplementary Figure 2a. Pure rice husk (untreated) is mainly composed of cellulose, hemicellulose, lignin, silica, wax, and other moieties. The disappearance of the $800 \mathrm{~cm}^{-1}$ peaks from the chemically treated rice husk indicates the removal of the silica functional group. Furthermore, a disappearance of the $1517 \mathrm{~cm}^{-1}$ and $1640 \mathrm{~cm}^{-1}$ peaks from the chemically treated rice husk suggests the removal of the lignin structure [22].
The band at $1736 \mathrm{~cm}^{-1}$ in the spectrum of the raw rice husk is attributed to $\mathrm{C}=\mathrm{O}$ stretching of the acetyl and uronic ester groups of hemicellulose [23]. Significantly, a decrease in the $\mathrm{C}=\mathrm{O}$ stretching peak in the chemically treated rice husk demonstrated the removal of hemicellulose by the $\mathrm{NaOH}$ treatment. The appearance of the absorption peaks at 1040 and $896 \mathrm{~cm}^{-1}$ in the chemically treated sample indicates the presence of the $\mathrm{C}-\mathrm{O}$ stretching and $\mathrm{C}-\mathrm{H}$ rock vibrations of cellulose [24]. Furthermore, the appearance of an absorption peak at $3360 \mathrm{~cm}^{-1}$ in FTIR spectra suggested the presence of hydroxyl moiety (-OH stretching) in the sample. Thermal stability is another important parameter of the material, reflecting material stability for a wide range of applications. TGA thermograms of the pure rice husk and chemically treated sample are given in Supplementary Figure $2 \mathrm{~b}$. Both the samples exhibited a similar kind of degradation pattern, starting at $252^{\circ} \mathrm{C}$ and $375^{\circ} \mathrm{C}$. However, early-stage $\left(\sim 100^{\circ} \mathrm{C}\right)$ degradation was due to the moisture. It has been reported that a decrease in thermal stability is observed in the chemically treated sample than pure rice husk [25]. It was interesting to see that the chemically treated sample had more thermal stability than the untreated one at the lower temperature $\left(<300^{\circ} \mathrm{C}\right)$. This was due to the presence of a more compact cellulose structure, which restricts the evaporation of volatile mass [26]. However, above the $300^{\circ} \mathrm{C}$, the stability of the chemically treated sample decreases compared with that of pure rice husk. This is attributed to the presence of lignin moieties in the pure sample, which confers better stability on them [27]. Surface morphologies of pure rice husk and the chemically treated 


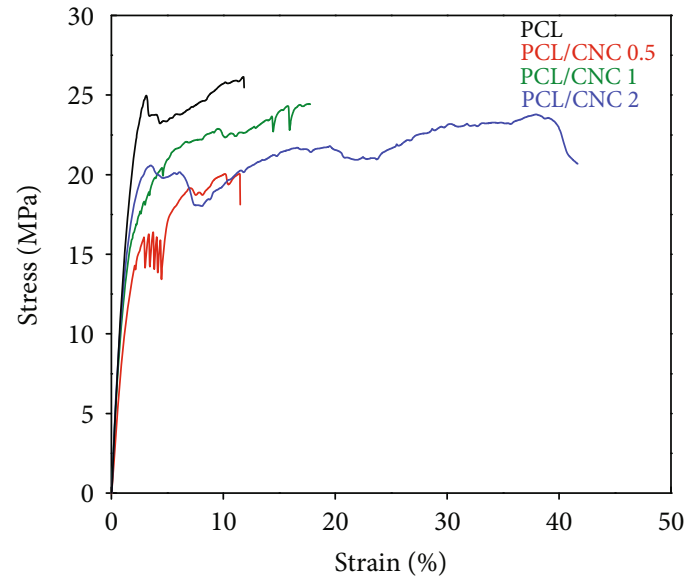

(a)

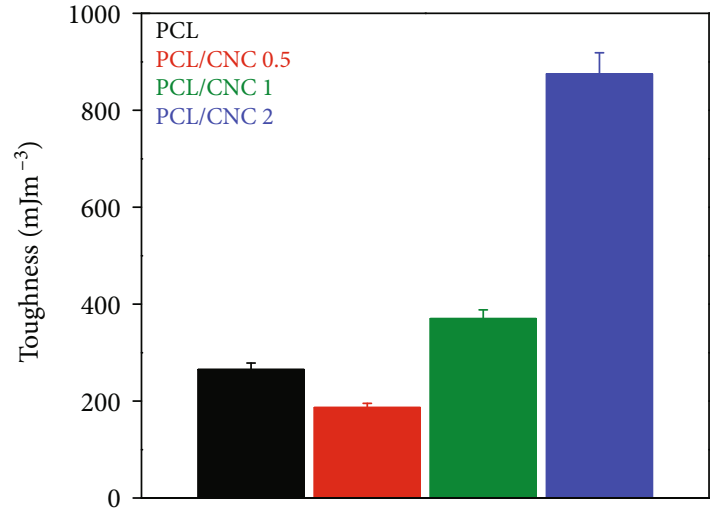

(b)

FIGURE 4: The mechanical properties of the fabricated scaffolds. (a) The strain-stress curve and (b) the bar diagram representation of peak stress values of different PCL/CNC composites under uniaxial tensile test.

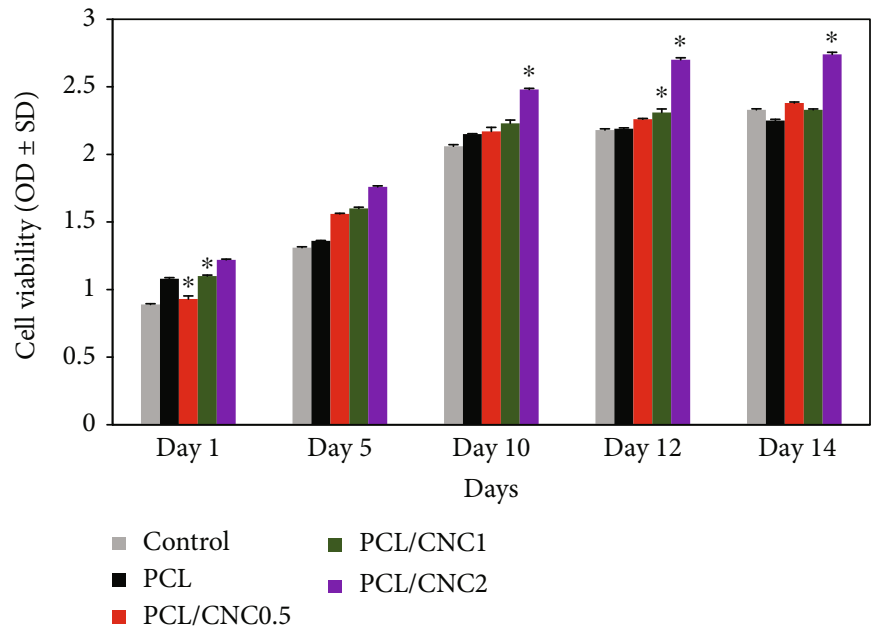

FIGURE 5: Cytotoxicity evaluation of the pure PCL and indicated composite nanofibers in the presence of hMSCs at indicated time intervals $\left({ }^{*} P<0.05\right)$.

sample are given in Supplementary Figure 2c. The pure rice husk sample exhibited a relatively smooth surface morphology compared with that of the chemically treated sample, on which cellulose layers appeared as microfibrils. The sample before acid hydrolysis is termed as the chemically treated sample in this manuscript.

3.2. Morphology of CNCs. It is well known that cleavage of the glycosidic linkage of the cellulose structure occurs in the presence of an acidic environment. These cleavages of the glycosidic linkage are responsible for the generation of nanodimensional cellulose moieties known as nanocellulose. Figure 3(a) shows the TEM image of the obtained CNCs after the sulfuric acid hydrolysis. The mean CNC length and width were $93.31 \mathrm{~nm}$ and $27.5 \mathrm{~nm}$, respectively. The TEM image of the hydrolyzed sample indicated the removal of the amorphous zones from the cellulose structure and produced the highly ordered and crystalline structure. The dis- tribution length and width of the obtained CNCs are shown in Figure 3(b). The mean length and width of the obtained CNCs are similar to the previously reported values [28].

3.3. Mechanical Properties of PCL/CNC Composite. The mechanical properties of fabricated composites under uniaxial stress (stress-strain curve) through a universal tensile machine (UTM) are given in Figure 4(a). The mechanical properties are highly influenced by the nature as well as dispersion level of the nanofiller in the polymer matrix. The significant enhancement in the elongation at break was observed with the composites but not with the pure polymer. This is due to the better interactions between the polymer matrix and CNC that inhibited the crack propagation process during the experiment by orienting the individual CNCs towards the applied force. The toughness of the polymer and their indicated composites measured under stressstrain area are shown in Figure 4(b). It was interesting to 


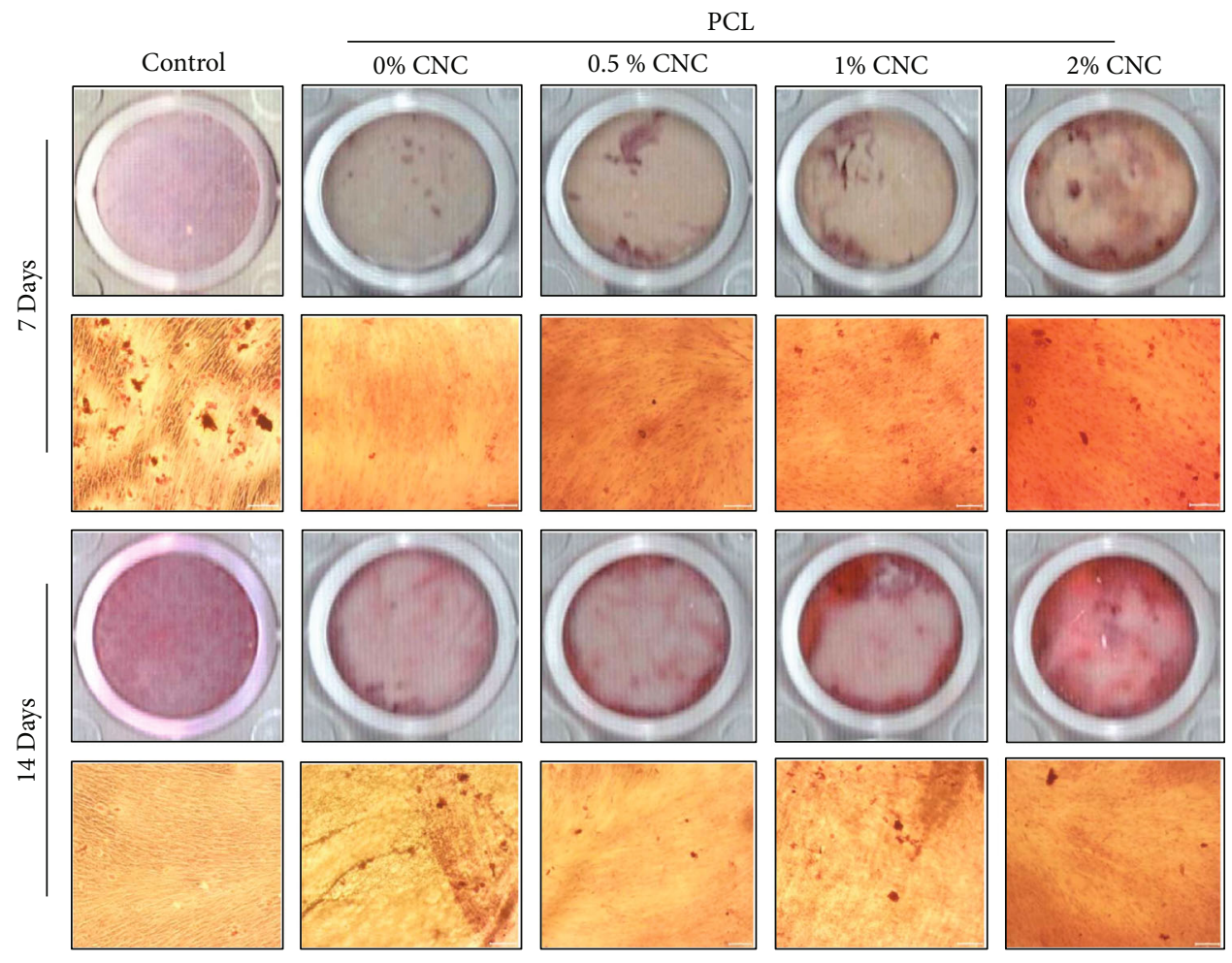

(a)
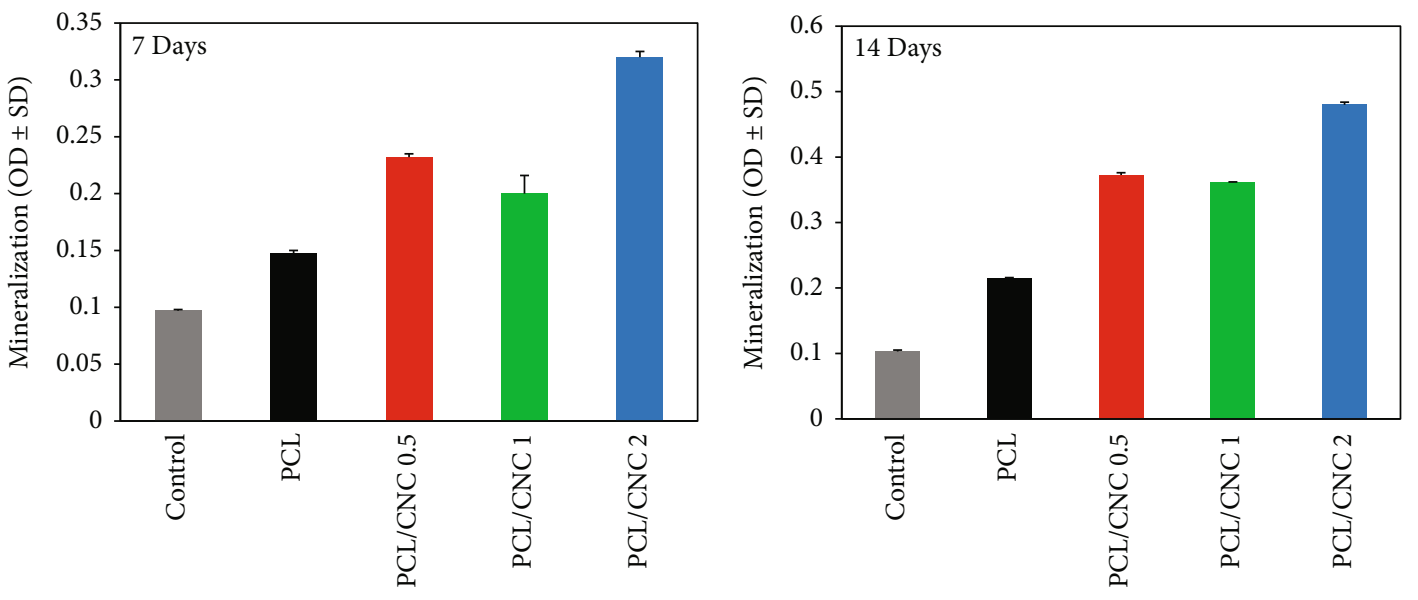

(b)

FIGURE 6: Evaluation of osteogenic differentiation potential of hMSCs in the presence of the pure PCL and indicated composite after 7 and 14 days of treatment. (a) ARS staining of cultured hMSCs along with corresponding optical images in the presence of the pure PCL and indicated composite. (b) Mineralization study after 7 days and 14 days of incubation. The medium without sample was used as control.

see that composites were tougher than the pure polymer. The higher aspect ratio of $\mathrm{CNC}$ enables a better platform for interactions and consequently improves the overall mechanical properties. An improvement in the thermal and mechanical properties has already been reported in MPLA/CNC composites [29].

3.4. Cell Viability and Differentiation. For biomedical applications, the material should be nontoxic and biodegradable. Also, the material should not elicit any kind of adverse immune response in surrounding conditions. Cell viability of the fabricated scaffolds was evaluated by the WST-1 assay technique in the presence of hMSCs after 14 days of incubation (Figure 5). An enhancement in the cell viability was observed in the presence of the fabricated scaffolds compared to the control values. Cell viability was highly influenced by the content of the CNCs in the polymer matrix. It was observed that as the content of $\mathrm{CNC}$ increased, the cell viability improved. However, the maximum cell viability was found in the presence of $2 \% \mathrm{CNC}$ at day 14 of incubation, indicating that $2 \% \mathrm{CNC}$ is the optimum content for scaffold fabrication as well as cell growth. 


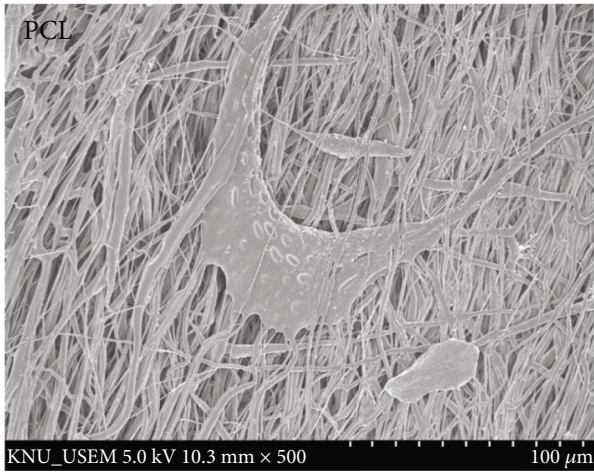

(a)

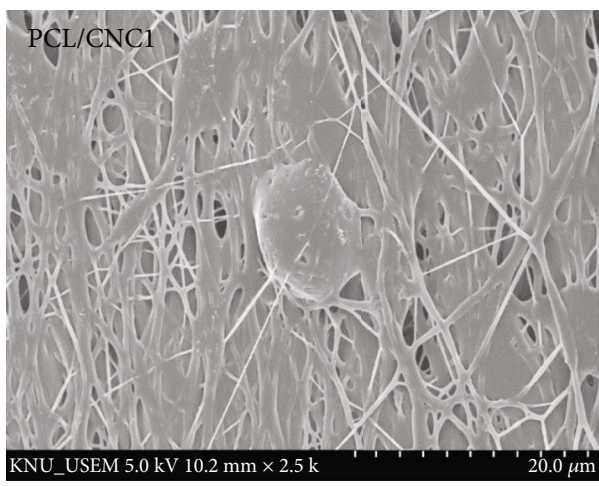

(c)

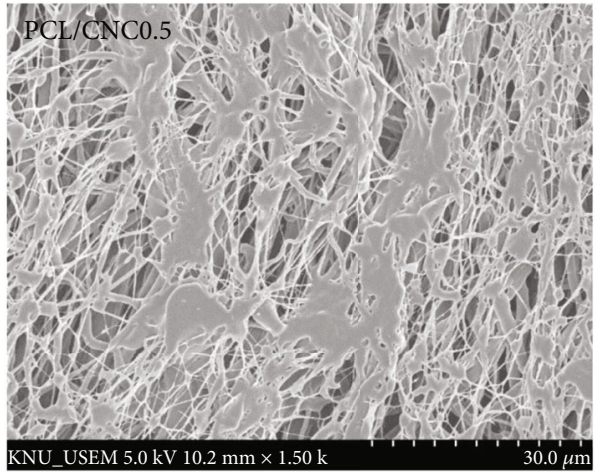

(b)

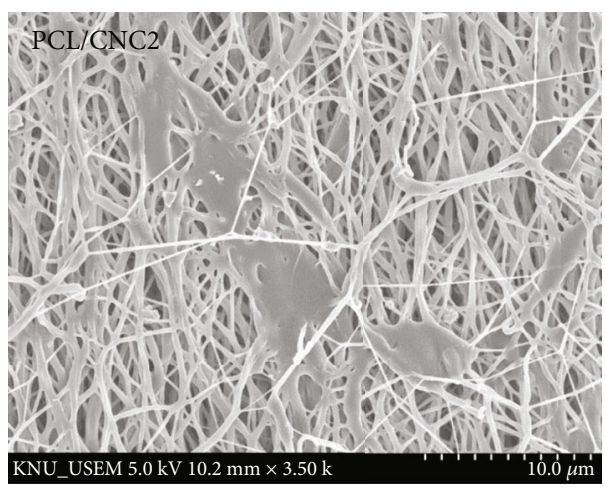

(d)

FIGURE 7: FE-SEM morphologies of hMSCs cultured on the surface of pure PCL and indicated composite nanofibers.

These results confirmed the noncytotoxicity of the fabricated scaffolds. The porosity and the higher surface area of the fabricated electrospun fabrics facilitate the better conditions for cellular activity [30]. Cell viability in the presence of the CNCs at different amounts after $24 \mathrm{~h}$ and $48 \mathrm{~h}$ is shown in Supplementary Figure 3. No significant adverse effect was observed on hMSCs after $48 \mathrm{~h}$ of incubation in the presence of CNCs, indicating the biocompatibility of CNCs. The mineralization test was carried out using the ARS solution. Osteogenesis depends on the structure and properties of the scaffold material [31]. Thus, electrospun polymer nanofiber with bioactive substances can further improve the biomimetic properties of nanofibrous scaffolds and enhance cell attachment, proliferation, and differentiation [32]. ARS staining of the hMSCs cultured for 7 and 14 days was performed to evaluate the effect of the fabricated scaffolds on cell differentiation. The presence of $2 \%$ CNCs significantly enhanced cell differentiation after 7 days of incubation. More interestingly, enhancement of cell differentiation was observed even after 2 weeks. The quantification of ARS staining of the PCL/CNC composites is shown in Figure 6(b). Furthermore, it was interesting to note that the mineralization decreased in the presence of pure PCL scaffolds after 7 and 14 days relative to the control values and hence $2 \% \mathrm{CNCs}$ is the optimum content for mineralization. Scaffolds stained after 1 and 2 weeks of incubation are shown in Figure 6(a). A more intense staining was observed with $2 \% \mathrm{PCL} / \mathrm{CNC}$ composites in comparison with the other groups after 7 and 14 days of incubation, further confirming the greater osteogenic potential of hMSCs in the presence of $2 \% \mathrm{PCL} / \mathrm{CNCs}$. CNCs have previously proven to be suitable as implant materials [33]. Furthermore, CNC-based materials can promote osteoblast attachment, migration, and proliferation and can thus act as promising materials for future applications in bone therapies [34].

3.5. Cell-Matrix Interactions. Proper adhesion onto the extracellular matrix (ECM) is important for viability and proliferation of hMSCs. Thus, surface modification using various scaffolds is a promising strategy for bone engineering $[35,36]$. In our present study, the cell adhesion efficiency of hMSCs in the presence of PCL/CNC nanocomposites was evaluated by SEM morphology after 5 days of incubation (Figure 7). The SEM morphology confirmed that the cells were properly attached to the fabricated PCL/CNC scaffolds by filopodia-like structures. A similar study has been conducted by Chan et al. using poly(L-lactate-polycaprolactone)/collagen (PLLA-CL/COL) electrospun nanofibers to evaluate the efficiency of hBMSC adhesion [37]. The same group has reported that hBMSC adhesion increased in a time-dependent manner. A recent has study also shown that hydroxyapatite/PCL scaffolds can increase the viability as well as osteogenic potential of the cells by promoting them to adhere onto the surface of the scaffolds [36]. Our results suggested that the cell adhesion was better with PCL/CNC0.5 and PCL/CNC1 than with the pure PCL 

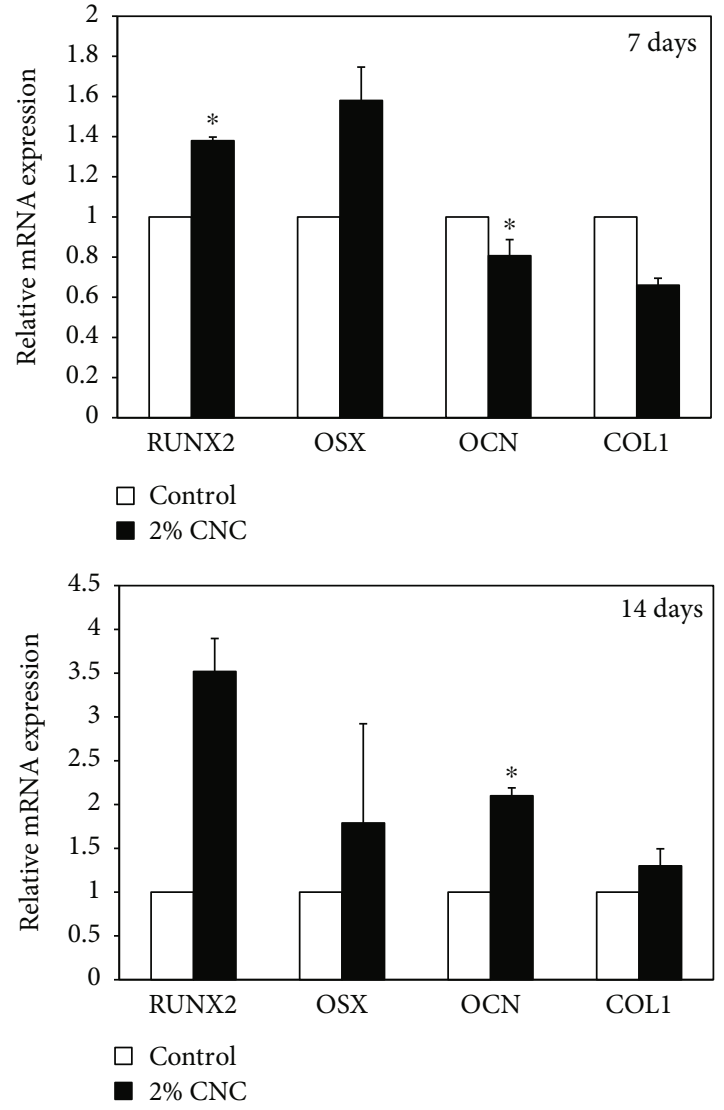

FIGURE 8: Real-time PCR (qRT-PCR) analysis for the expression of osteogenesis-specific genes (RUNX1, OSX, OCN, and COL1) in the presence of $2 \%$ PCL/CNC composites after 7 and 14 days of incubation $\left({ }^{*} P<0.05\right)$.

(Figures 7(b) and 7(c)). Taken together, our results indicated that PCL/CNC nanocomposites could be an ideal candidate for bone engineering.

3.6. Quantitative Real-Time PCR (qRT-PCR) Analysis. Real-time PCR was performed to evaluate the differentially expressed genes during osteogenesis. The levels of the differentiation-specific genes in the presence of $2 \%$ PCL/CNC scaffolds were evaluated by qRT-PCR after 7 and 14 days of incubation (Figure 8). Osteogenic induction medium without the PCL/CNC scaffolds was considered as control. Generally, hMSCs are multipotential cells that can differentiate into preosteoblasts and osteoblasts (mature bone). Because of various external and internal stimuli, gene switching randomly occurs, leading to the activation or deactivation of different sets of genes (e.g., RUNX2, OSX, ALP, BMP, OCN, OPN, and COL1) [38]. RUNX2 (Runt-related transcription factor 2) and OSX (Osterix) marker are directly related to the preosteoblast formation, and OCN (osteocalcin; bone $\gamma$-carboxyglutamate protein), OPN (osteopontin), and COL1 (collagen type 1) are related to mature osteoblast formation [39, 40]. Here, we used 2\% PCL/CNC composites to evaluate the relative gene expression levels because the mineralization efficiency was higher with $2 \%$ PCL/CNCs than with other concentrations.
Although the osteogenic genes (e.g., RUNX2, OSX, OCN, and COL1) were also expressed with the control medium containing hMSCs, their expression was higher in the presence of $2 \%$ PCL/CNCs. Initially, there was a decrease in RUNX2 expression for 7 days, but interestingly, it rapidly increased by approximately 2.02-2.42-fold relative to that of the control by day 14. Similarly, there is an increase in the expression of OCN $(\sim 1.3$-fold $)$ in the day 14 samples except for COL1 ( 0.5-fold) compared with the control values. These results indicate their enhanced osteogenic nature in the presence of $2 \%$ PCL/CNCs. RUNX2 is critical for preosteoblast differentiation. Our results suggest that in the presence of $2 \%$ PCL/CNC composites, osteogenesis of hMSCs is enhanced. Hence, CNC/PCL-based composites can potentially be used as biomaterials for bone engineering.

\section{Conclusions}

In this study, we evaluated the synergistic effects of the PCL/CNC composites in terms of mechanical properties, cell viability, and induction of osteogenesis. The CNCs were extracted from rice husk biomass and characterized by the TEM. No significant cytotoxicity was exhibited by the obtained CNCs. A significant improvement in mechanical properties occurred in the fabricated scaffolds indicating the more significant interactions between PCL and CNCs. In addition, the cell viability enhanced in the presence of the fabricated nanofibers indicating their biocompatibility. Importantly, significant mineralization of the hMSCs occurred when the CNC content of the scaffolds was high (2\%) indicating that the hMSCs were induced to undergo osteogenesis by synergistic effects. Moreover, the RUNX2 and OCN expressions were also upregulated in the presence of $2 \%$ PCL/CNC composites. On the basis of these results, we concluded that the fabricated nanofibers can serve as a biomaterial for tissue engineering applications. We hope that this approach for fabrication of PCL/CNC-based composites will open a new direction in tissue engineering.

\section{Data Availability}

The data used to support the findings of this study are available from the corresponding author upon request.

\section{Conflicts of Interest}

The authors declare no conflict of interest.

\section{Authors' Contributions}

Sayan Deb Dutta and Dinesh K. Patel contributed equally to this work.

\section{Acknowledgments}

This research was supported by the Basic Science Research Program through the National Research Foundation of Korea (NRF) funded by the Ministry of Education (No. 2018R1A6A1A03025582 and No. 2016R1D1 A3B03932921). The authors also acknowledge the Cooperative Research 
Program for Agriculture Science and Technology Development (No. PJ012854012017), Rural Development Administration.

\section{Supplementary Materials}

Supplementary Figure 1: the photograph of the (a) pure rice husk, (b) the chemically treated samples, and (c) CNC suspension, isolated from rice husk. Rice husk powder (10 g) was used for the generation of CNCs. The extracted CNCs were lyophilized and stored in a sealed container prior to use. Approximately $2.9 \mathrm{~g}$ CNC was regenerated from $10 \mathrm{~g}$ of pure rice husk. Supplementary Figure 2: spectroscopic characterization of pure rice husk and the chemically treated sample: (a) FTIR spectra, (b) TGA thermograms, and (c) SEM morphology ( $\mathrm{i}$ and ii) of pure rice husk and the chemically treated sample showing the roughness before and after treatment. Both the samples exhibited a similar kind of degradation pattern, starting at $252^{\circ} \mathrm{C}$ and $375^{\circ} \mathrm{C}$ as indicated in TGA analysis. However, early-stage $\left(\sim 100^{\circ} \mathrm{C}\right)$ degradation was due to the moisture. The disappearance of the $800 \mathrm{~cm}^{-1}$ peaks from the chemically treated rice husk indicates the removal of the silica functional group as shown in FTIR spectra. Supplementary Figure 3: cell viability data of hMSCs in the presence of different CNC concentrations after 24 and $48 \mathrm{~h}$ of incubation and is evaluated by WST-1 assay. Results were represented as percentage of triplicate experiments $\left({ }^{*} P<0.05\right)$. Increased cell viability was found in the presence of $2 \% \mathrm{CNC}$ after $24 \mathrm{~h}$ of incubation as compared to the control and other groups. (Supplementary Materials)

\section{References}

[1] B. Dhandayuthapani, Y. Yoshida, T. Maekawa, and D. S. Kumar, "Polymeric scaffolds in tissue engineering application: a review," International Journal of Polymer Science, vol. 2011, Article ID 290602, 19 pages, 2011.

[2] D. W. Hutmacher, "Scaffolds in tissue engineering bone and cartilage," Biomaterials, vol. 21, no. 24, pp. 2529-2543, 2000.

[3] W. Luo, L. Cheng, C. Yuan et al., "Preparation, characterization and evaluation of cellulose nanocrystal/poly(lactic acid) in situ nanocomposite scaffolds for tissue engineering," International Journal of Biological Macromolecules, vol. 134, pp. 469-479, 2019.

[4] H. Yan, D. Huang, X. Chen et al., "A novel and homogeneous scaffold material: preparation and evaluation of alginate/bacterial cellulose nanocrystals/collagen composite hydrogel for tissue engineering," Polymer Bulletin, vol. 75, no. 3, pp. 9851000, 2018.

[5] S. Agarwal, J. H. Wendorff, and A. Greiner, "Use of electrospinning technique for biomedical applications," Polymer, vol. 49, no. 26, pp. 5603-5621, 2008.

[6] Q. P. Pham, U. Sharma, and A. G. Mikos, "Electrospinning of polymeric nanofibers for tissue engineering applications: a review," Tissue Engineering, vol. 12, no. 5, pp. 1197-1211, 2006.

[7] Q. Shi, C. Zhou, Y. Yue, W. Guo, Y. Wu, and Q. Wu, "Mechanical properties and in vitro degradation of electrospun bionanocomposite mats from PLA and cellulose nanocrystals," Carbohydrate Polymers, vol. 90, no. 1, pp. 301-308, 2012.
[8] Z. M. Huang, Y. Z. Zhang, M. Kotaki, and S. Ramakrishna, "A review on polymer nanofibers by electrospinning and their applications in nanocomposites," Composites Science and Technology, vol. 63, no. 15, pp. 2223-2253, 2003.

[9] N. Siddiqui, S. Asawa, B. Birru, R. Baadhe, and S. Rao, "PCLbased composite scaffold matrices for tissue engineering applications," Molecular Biotechnology, vol. 60, no. 7, pp. 506-532, 2018.

[10] S. J. Cho, S. M. Jung, M. Kang, H. S. Shin, and J. H. Youk, "Preparation of hydrophilic PCL nanofiber scaffolds via electrospinning of PCL/PVP-b-PCL block copolymers for enhanced cell biocompatibility," Polymer, vol. 69, pp. 95-102, 2015.

[11] J. George, M. Sreekala, and S. Thomas, "A review on interface modification and characterization of natural fiber reinforced plastic composites," Polymer Engineering and Science, vol. 41, no. 9, pp. 1471-1485, 2001.

[12] C. Salas, T. Nypelö, C. Rodriguez-Abreu, C. Carrillo, and O. J. Rojas, "Nanocellulose properties and applications in colloids and interfaces," Current Opinion in Colloid \& Interface Science, vol. 19, no. 5, pp. 383-396, 2014.

[13] R. M. Domingues, S. Chiera, P. Gershovich, A. Motta, R. L. Reis, and M. E. Gomes, "Enhancing the biomechanical performance of anisotropic nanofibrous scaffolds in tendon tissue engineering: reinforcement with cellulose nanocrystals," Advanced Healthcare Materials, vol. 5, no. 11, pp. 13641375, 2016.

[14] Y. Habibi, L. A. Lucia, and O. J. Rojas, "Cellulose nanocrystals: chemistry, self-assembly, and applications," Chemical Reviews, vol. 110, no. 6, pp. 3479-3500, 2010.

[15] Y. R. Seo, J. W. Kim, S. Hoon, J. Kim, J. H. Chung, and K. T. Lim, "Cellulose-based nanocrystals: sources and applications via agricultural byproducts," Journal of Biosystems Engineering, vol. 43, no. 1, pp. 59-71, 2018.

[16] A. Ghanbari, T. Tabarsa, A. Ashori, A. Shakeri, and M. Mashkour, "Thermoplastic starch foamed composites reinforced with cellulose nanofibers: thermal and mechanical properties," Carbohydrate Polymers, vol. 197, pp. 305-311, 2018.

[17] A. Sinha, E. M. Martin, K. T. Lim et al., "Cellulose nanocrystals as advanced "green" materials for biological and biomedical engineering," Journal of Biosystems Engineering, vol. 40, no. 4, pp. 373-393, 2015.

[18] C. A. Ariza, A. T. Fleury, C. J. Tormos et al., "The influence of electric fields on hippocampal neural progenitor cells," Stem Cell Reviews and Reports, vol. 6, no. 4, pp. 585-600, 2010.

[19] L. Ludueña, D. Fasce, V. A. Alvarez, and P. M. Stefani, "Nanocellulose from rice husk following alkaline treatment to remove silica," Bio Resources, vol. 6, no. 2, pp. 1440-1453, 2011.

[20] A. Daifullah, N. Awwad, and S. El-Reefy, "Purification of wet phosphoric acid from ferric ions using modified rice husk," Chemical Engineering and Processing: Process Intensification, vol. 43, no. 2, pp. 193-201, 2004.

[21] J. T. Y. Lee and K. L. Chow, "SEM sample preparation for cells on 3D scaffolds by freeze-drying and HMDS," Scanning, vol. 34, no. 1, 25 pages, 2012.

[22] Y. J. Lee, W. Jang, H. Im, and J. S. Sung, "Extremely low frequency electromagnetic fields enhance neuronal differentiation of human mesenchymal stem cells on graphene-based substrates," Current Applied Physics, vol. 15, pp. 95-102, 2015.

[23] X. Sun, F. Xu, R. Sun, P. Fowler, and M. Baird, "Characteristics of degraded cellulose obtained from steam-exploded wheat 
straw," Carbohydrate Research, vol. 340, no. 1, pp. 97-106, 2005.

[24] R. M. Sheltami, I. Abdullah, I. Ahmad, A. Dufresne, and H. Kargarzadeh, "Extraction of cellulose nanocrystals from mengkuang leaves (Pandanus tectorius)," Carbohydrate Polymers, vol. 88, no. 2, pp. 772-779, 2012.

[25] A. Alemdar and M. Sain, "Isolation and characterization of nanofibers from agricultural residues-wheat straw and soy hulls," Bioresource Technology, vol. 99, no. 6, pp. 1664-1671, 2008.

[26] M. Roman and W. T. Winter, "Effect of sulfate groups from sulfuric acid hydrolysis on the thermal degradation behavior of bacterial cellulose," Biomacromolecules, vol. 5, no. 5, pp. 1671-1677, 2004.

[27] H. Zhang, Y. Xu, Y. Li et al., "Facile cellulose dissolution and characterization in the newly synthesized 1, 3-diallyl-2-ethylimidazolium acetate ionic liquid," Polymers, vol. 9, no. 12, pp. 526-528, 2017.

[28] H. Y. Mi, X. Jing, J. Peng, M. R. Salick, X. F. Peng, and L. S. Turng, "Poly ( $\varepsilon$-caprolactone)(PCL)/cellulose nano-crystal (CNC) nanocomposites and foams," Cellulose, vol. 21, no. 4, pp. 2727-2741, 2014.

[29] N. Johar and I. Ahmad, "Morphological, thermal, and mechanical properties of starch biocomposite films reinforced by cellulose nanocrystals from rice husks," Bio Resources, vol. 7, pp. 5469-5477, 2012.

[30] C. Zhou, Q. Shi, W. Guo et al., "Electrospun bionanocomposite scaffolds for bone tissue engineering by cellulose nanocrystals reinforcing maleic anhydride grafted PLA," ACS Applied Materials \& Interfaces, vol. 5, no. 9, pp. 38473854, 2013.

[31] H. Yoshimoto, Y. Shin, H. Terai, and J. Vacanti, "A Biodegradable nanofiber scaffold by electrospinning and its potential for bone tissue engineering," Biomaterials, vol. 24, no. 12, pp. 2077-2082, 2003.

[32] S. Kwak, A. Haider, K. C. Gupta, S. Kim, and I. K. Kang, "Micro/nano multilayered scaffolds of PLGA and collagen by alternately electrospinning for bone tissue engineering," Nanoscale Research Letters, vol. 11, no. 1, pp. 323-339, 2016.

[33] M. E. Frohbergh, A. Katsman, G. P. Botta et al., "Electrospun hydroxyapatite-containing chitosan nanofibers crosslinked with genipin for bone tissue engineering," Biomaterials, vol. 33, no. 36, pp. 9167-9178, 2012.

[34] Q. Chen, R. P. Garcia, J. Munoz et al., "Cellulose nanocrystals bioactive glass hybrid coating as bone substitutes by electrophoretic co-deposition: in situ control of mineralization of bioactive glass and enhancement of osteoblastic performance," ACS Applied Materials \& Interfaces, vol. 7, no. 44, pp. 24715-24725, 2015.

[35] J. H. Lee, J. H. Park, Y. R. Yun et al., "Tethering bi-functional protein onto mineralized polymer scaffolds to regulate mesenchymal stem cell behaviors for bone regeneration," Journal of Materials Chemistry B, vol. 1, no. 21, pp. 2731-2741, 2013.

[36] V. D'Anto, M. G. Raucci, V. Guarino, S. Martina, R. Valletta, and L. Ambrosio, "Behaviour of human mesenchymal stem cells on chemically synthesized HA-PCL scaffolds for hard tissue regeneration," Journal of Tissue Engineering and Regenerative Medicine, vol. 10, no. 2, pp. E147-E154, 2016.

[37] C. K. Chan, S. Liao, B. Li et al., "Early adhesive behavior of bone-marrow-derived mesenchymal stem cells on collagen electrospun fibers," Biomedical Materials, vol. 4, p. 035006, 2009.
[38] H. Jafari, M. Shahrousvand, and B. Kaffashi, "Reinforced poly ( $\varepsilon$-caprolactone) bimodal foams via phospho-calcified cellulose nanowhisker for osteogenic differentiation of human mesenchymal stem cells," ACS Biomaterials Science \& Engineering, vol. 4, no. 7, pp. 2484-2493, 2018.

[39] T. Schilling, U. Nöth, L. Klein-Hitpass, F. Jakob, and N. Schütze, "Plasticity in adipogenesis and osteogenesis of human mesenchymal stem cells," Molecular and Cellular Endocrinology, vol. 271, no. 1-2, pp. 1-17, 2007.

[40] K. Nakashima, X. Zhou, G. Kunkel et al., "The Novel Zinc Finger-Containing Transcription Factor Osterix Is Required for Osteoblast Differentiation and Bone Formation," Cell, vol. 108, no. 1, pp. 17-29, 2002. 


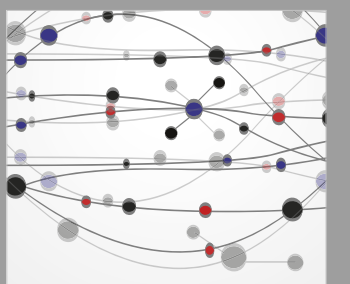

The Scientific World Journal
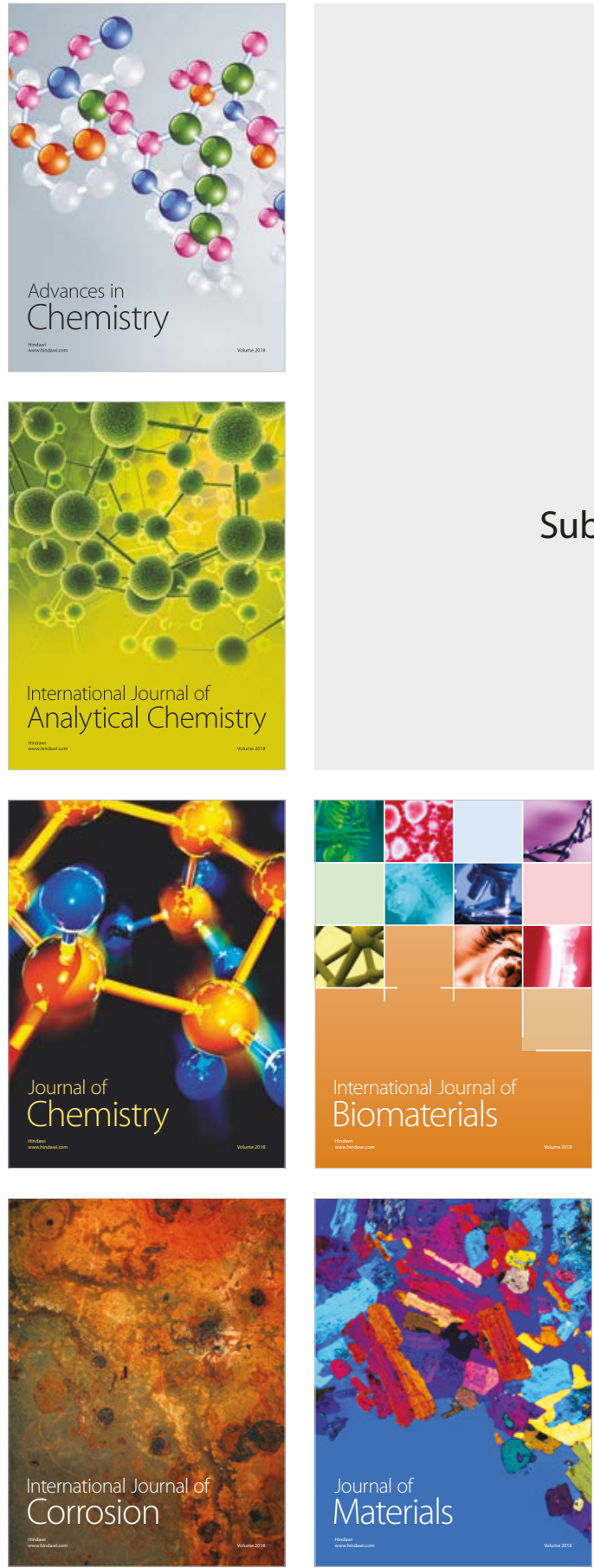

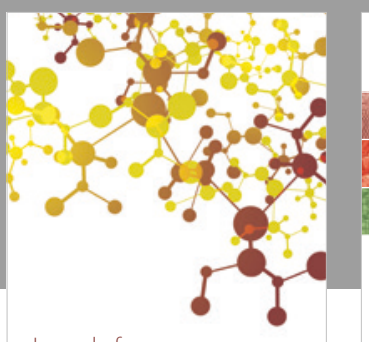

Journal of

Applied Chemistry
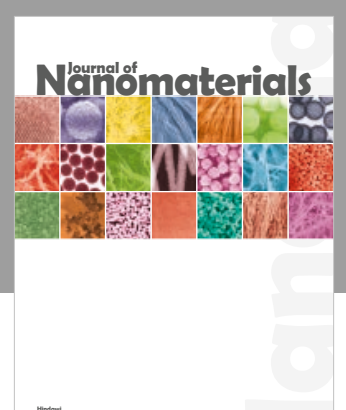

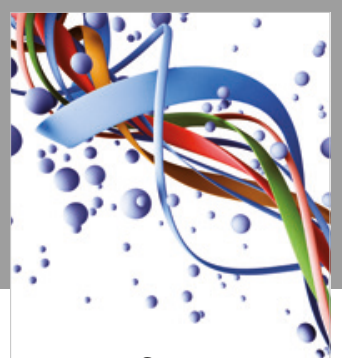

Scientifica

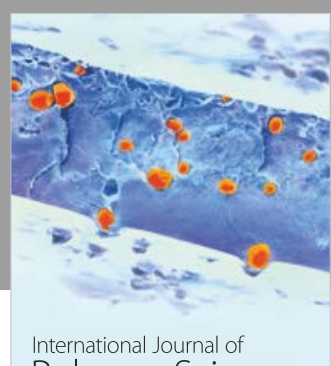

Polymer Science

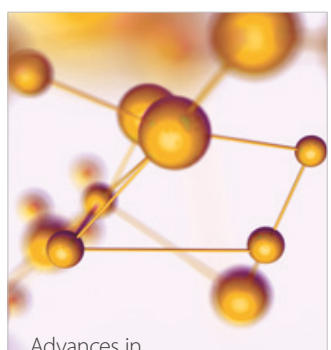

Physical Chemistry
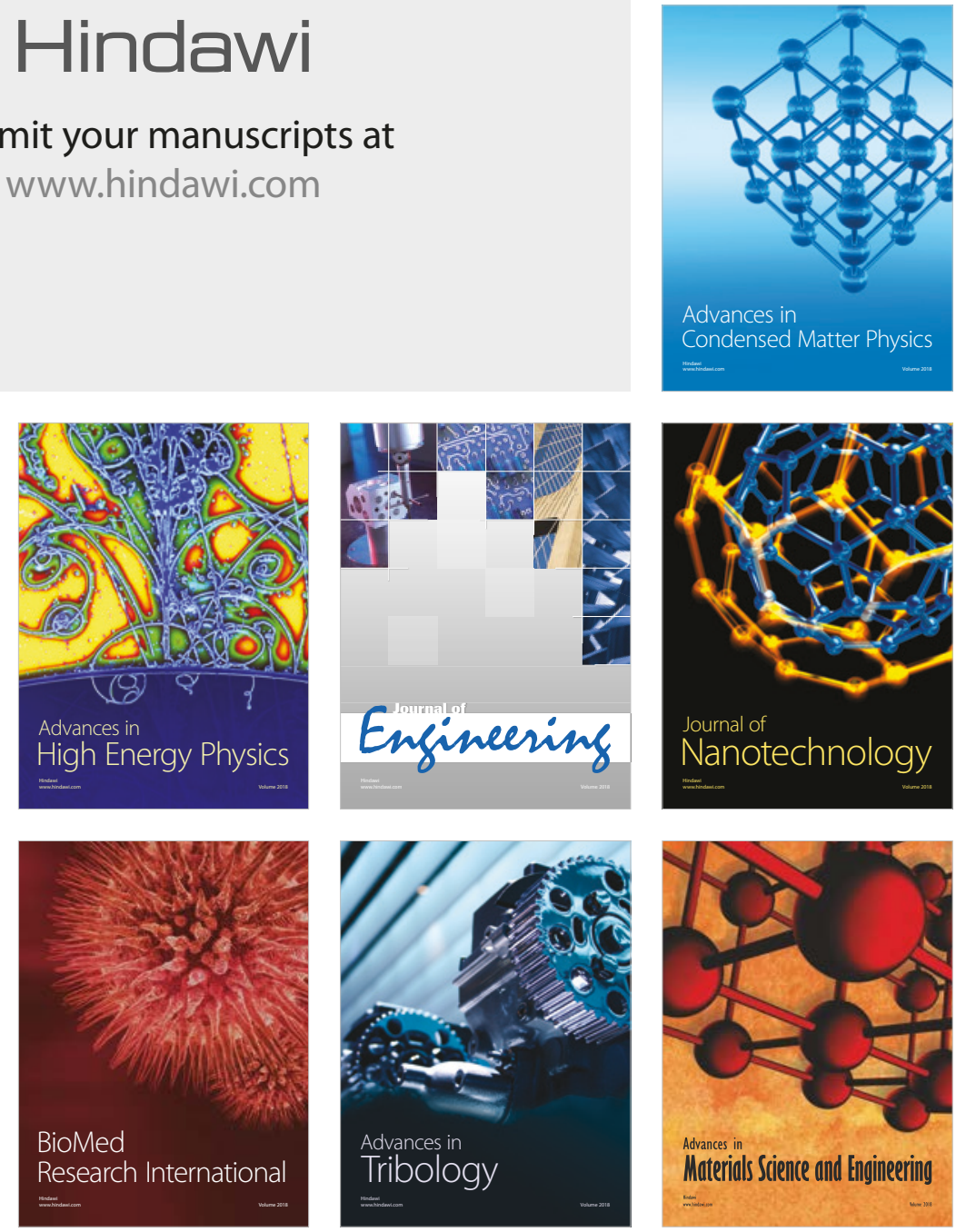